\title{
The influence of color on transient system activity: Implications for dyslexia research
}

\author{
KRISTEN PAMMER and W. LOVEGROVE \\ University of Wollongong, Wollongong, New South Wales, Australia
}

\begin{abstract}
Metacontrast and apparent motion experiments designed to utilize transient system resources were adopted to investigate the proposal that transient system activity is differentially influenced by different colored stimuli. The results generally showed no effect of color on transient system activity in either adults or children. However, the predicted pattern of results was demonstrated when contrast rather than color was manipulated in a final metacontrast experiment. We discuss the tenuousness of the proposal that color differentially influences transient activity, exploring its physiological implications and its durability as a theory of transient activity regarding reading-disability research.
\end{abstract}

The visual system is generally operationalized in terms of parallel subsystems that are specialized for transmitting different types of visual information (see Breitmeyer, 1984, and Lennie, 1980, for reviews). The terms transient and sustained are commonly used in conjunction with anatomical data, whereas the terms magnocellular and parvocellular are typically used in anatomical/physiological research. The transient, or magnocellular, system is frequently considered to be color insensitive, color vision being the domain of the sustained, or parvocellular, system (e.g., Hicks, Lee, \& Vidyasager, 1983; Kruger, 1979; Livingstone \& Hubel, 1987). However, while complex color processing remains a characteristic of the sustained system, the transient system does demonstrate some evidence of rudimentary color discrimination, such that activity may be attenuated under red stimulus conditions. This property has been demonstrated both anatomically and psychophysically (e.g., Edwards, Hogben, Clark, \& Pratt, 1996; Wiesel \& Hubel, 1966). However, it has been suggested that transient activity may not only be attenuated by red stimuli but also increased or enhanced by blue light conditions (Williams, Breitmeyer, Lovegrove, \& Gutierrez, 1991; Williams, LeCluyse, \& Faucheux, 1990, cited in Williams \& Lovegrove, 1992). This is an intriguing possibility; no anatomical study has demonstrated that different colors may differentially influence transient activity.

Portions of this article are included in a doctoral dissertation submitted to Wollongong University by the first author, who was supported by Large ARC Grant Funding. The authors thank two anonymous reviewers for essential comments on an earlier version of this paper. W. Lovegrove is now at the DVC Unit, Griffith University, Nathan Campus, Brisbane, Queensland, Australia. Correspondence should be addressed to K. Pammer, who is now at the Department of Psychology, University of Newcastle, Newcastle-upon-Tyne, NE1 7RU, England (e-mail: kristen.pammer@ncl.ac.uk).
Notwithstanding the theoretical arguments, the practical implications of a transient system that is differentially influenced by different color stimuli are enormously valuable for systems of remediation in dyslexia, the etiology of which is hypothesized to stem from a transient system deficit. The evidence presented to support a transient system deficit in dyslexia is persuasive in its convergence and includes measures of visible persistence (Slaghuis \& Lovegrove, 1985), contrast sensitivity (Lovegrove, Bowling, Badcock, \& Blackwood, 1980), flicker contrast sensitivity (Brannan \& Williams, 1988; Martin \& Lovegrove, 1987), flicker sensitivity over spatial frequency (Martin \& Lovegrove, 1987), visual masking (Williams \& LeCluyse, 1990; Williams, LeCluyse, \& Bologna, 1990; Williams, Molinet, \& LeCluyse, 1989), coherent motion (Cornelissen, Richardson, Mason, Fowler, \& Stein, 1995), visual evoked potentials (Lehmkuhle, Garzia, Turner, Hash, \& Baro, 1993; May, Dunlap, \& Lovegrove, 1992; May, Lovegrove, Martin, \& Nelson, 1991) and anatomical evidence (Livingstone, Rosen, Drislane, \& Galaburda, 1991). Although the most parsimonious explanation is frequently the most appealing, the transient deficit theory is nevertheless not accepted without controversy (e.g., Gross-Glenn et al., 1995; Walther-Müller, 1995). Furthermore, there may be a case to be argued for the suggestion that evidence for a transient deficit may not be uniform but may be associated with one or more dyslexic categories or definitions.

\section{Transient System Activity, Dyslexia, and Color}

Practitioners of colored glasses have claimed some success in the use of colored lenses and overlays as a remedial technique for the scotopic sensitivity syndrome identified by Irlen (1983). However, consistent with the proposal that transient activity is differentially influenced by color stimuli, a simpler connection between color and 
reading ability has recently been proposed. A number of reading studies have demonstrated that broadband blue light, encompassing a range of wavelengths, increases reading performance, whereas broadband red light decreases reading performance (Greer \& Williams, 1995; Lovegrove \& Williams, 1993; Williams, LeCluyse, \& Rock-Faucheux, 1992). Blue light is believed to facilitate a normal time course in transient processing with readingdisabled individuals, thereby assisting their reading performance, whereas red light attenuates transient activity, resulting in a detrimental effect on reading. Recent suggestions have implicated insufficient magno-mediated feedback to the parvo system as the principal cause of the reading difficulty (Vidyasagar \& Pammer, 1999), but it is still unclear whether these feedback irregularities are due to latency or content abnormalities in the magno system, or both.

However, results from a number of studies manipulating broadband light conditions are equivocal. Psychophysical evidence in normal and dyslexic readers suggesting that transient activity is attenuated by red light has been demonstrated in measures of metacontrast (Breitmeyer \& Williams, 1990; Williams et al., 1991) and stroboscopic motion (Breitmeyer \& Williams, 1990), whereas other studies have demonstrated no effect of red stimuli (e.g., Breitmeyer \& Breier, 1993; Solman, Cho, \& Dain, 1991). Similarly, in measures of actual reading performance, Williams et al. (1992) found a decrease in reading comprehension when using red overlays on text with reading-disabled children, but they found no difference between red and gray overlays in normal readers; however, other studies have again demonstrated no effect of red stimuli (e.g., Legge \& Rubin, 1986). Similar conflict exists regarding the influence of blue light on transient activity and reading ability. For example, Williams et al. (1992) found an increase in reading comprehension with blue text for disabled readers, but they found a decrease in comprehension with normal readers. Greer and Williams (1995) demonstrated results consistent with an increase in transient activity under blue conditions in measures of reading comprehension, reading rate, and temporal order judgment for both dyslexic and normal readers. Conversely, Solman et al. (1991) found an effect of perceptual grouping only for normal readers. Conclusions regarding the effect that these color conditions have on the underlying physiology of the visual system are also compromised by the fact that color-particularly broadband color-and wavelength are by no means equivalent. One is a physical quality, whereas the other is a psychological phenomenon, and each may have different perceptual and theoretical consequences in this context.

Furthermore, the suggestion that blue stimuli enhance reading performance is in direct contrast to what is often reported in the Irlen lens literature. An important aspect in the reported success of Irlen lenses is the fact that the preferred lens color chosen by the reading-disabled individual is idiosyncratic, with colors ranging along almost all parts of the spectrum. Notwithstanding the possibility that the scotopic sensitivity syndrome may be a separate disorder to transient system dysfunction, given that researchers in both areas deal with reading-disabled individuals, one would expect the colored lens literature to have reported a general preference for shorter wavelength glasses if it is simply the case that exposure to blue stimuli increases transient activity, thereby facilitating reading for dyslexic readers.

In general, therefore, the proposal that transient activity may be differentially influenced by different color stimuli is controversial, as is the effect of color on more complex measures of actual reading performance.

\section{Aims of the Present Study}

If we accept that a transient system deficit may underlie some aspects of dyslexia, and it can be clearly demonstrated that broadband blue-colored text or overlays facilitate reading performance, then the possibility for simple large-scale remediation is enormous. However, given the discrepancies in the literature, further research is required to explore the suggestion that blue light and/or display conditions facilitate reading performance as a result of an increase in the magnitude of transient cell activity. Many of the aforementioned studies quite reasonably have used young children and/or a readingdisabled sample from which to draw their conclusions. However, given the number of conflicting results, together with the evidence that the transient system may be histologically different in the dyslexic population (Livingstone et al., 1991), a stronger justification for a differential effect of color on transient activity may be made if it can be clearly demonstrated in a large normal-reading adult sample, as well as a younger sample of normal and dyslexic readers. The aim of the present study was to directly investigate the possibility that transient activity is differentially affected by broadband colored stimuli in normal-reading adults, children, and dyslexic children, using perceptual tasks hypothesized to be directly related to transient system activity. A strong argument for the use of colored filters as a reading remediation technique could be maintained if it can be demonstrated that blue light increases transient activity and red light attenuates it in a large adult sample generally uncontaminated by perceptual deficiencies, color vision disorders, or reading disorders. It is predicted that if color can differentially affect transient activity to the magnitude required to make observable differences in reading performance, then such differences should also be apparent in psychophysical measures of transient activity.

\section{EXPERIMENT 1}

Metacontrast has been argued to reflect transient and sustained interactions, such that the $\mathrm{U}$-shaped function is directly related to transient-on-sustained inhibition. A decrease or an increase in the magnitude of the dip in the U-shaped function is believed to reflect a decrease or an increase, respectively, in the extent of transient-on-sustained inhibition (ergo, a decrease or an increase in the magnitude of transient activity; see Breitmeyer, 1984; Breit- 
meyer, May, \& Heller, 1991; Williams et al., 1991). It has been suggested that due to latency differences between the transient and sustained systems, maximum overlap between the transient response of the mask and the sustained response of the target results in transient-on-sustained inhibition at approximately $50 \mathrm{msec}$. Such inhibition results in a degradation in the perception of the target. At longer and shorter delays, the latency differences between the transient response of the mask and sustained response of the target are insufficient to cause maximum inhibition or maximum masking effects. Increases in the transient response of the mask should result in more masking and an increase in the masking function, whereas an attenuation of the transient response of the mask should result in a decrease in transient-on-sustained inhibition and a decrease in masking.

If blue light increases the activity of transient processing, and red light attenuates transient processing, then the $\mathrm{U}$-shaped function in the metacontrast paradigm under red conditions should result in a flattening of the function, whereas a deepening of the dip should characterize blue light conditions.

\section{Method}

Participants. Twenty-one individuals were recruited through advertisement in the local paper. Each participant was paid $\$ 10$ per experiment. The data for 2 participants was eliminated: one as a result of a color vision deficit, and the other as a result of a technical problem. No participant reported visual or cognitive problems that may have been reminiscent of a reading difficulty, and all had normal or corrected-to-normal vision and normal color vision.

Apparatus. The target/mask display was adapted from Hogben and Di Lollo (1984). The target consisted of a $5 \times 5 \mathrm{~mm}$ square composed of a $3 \times 3$ square matrix of points, subtending $0.6^{\circ}$ visual angle (VA). Each point on the matrix consisted of a single pixel dot, approximately $0.06^{\circ} \mathrm{VA}$. On each trial, one of the nine points (randomly determined) in the matrix was missing. The mask formed two complete $3 \times 3$ dot matrices, each subtending $0.6^{\circ} \times 0.6^{\circ} \mathrm{VA}$. Each dot of the two matrices consisted of a single pixel; the dots were separated by four pixel spaces. The mask was separated from the target by $4 \mathrm{~mm}\left(0.23^{\circ} \mathrm{VA}\right)$, and the target was centered between the two masks (see Figure 1).

The experiment was run on an IBM-compatible 386 PC, running with a Stealth graphics card. Displays were presented on a generic brand SVGA color monitor. The dots for each mask were colored red, gray, or blue $\left(5.4 / 3,5.4\right.$, or $\left.5.3 \mathrm{~cd} / \mathrm{m}^{2}\right)$, specified from a palette of 64 in Turbo Pascal Version 2. In all conditions, the colors of the displays were clearly discriminable. Isoluminance was measured

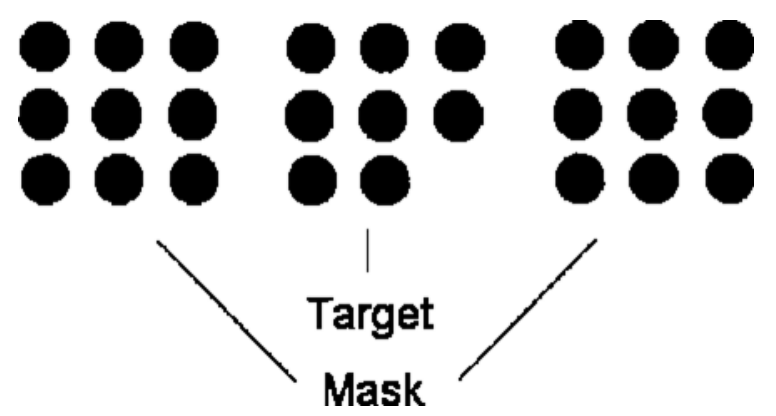

Figure 1. The target and mask display used in Experiments 1, 2 , and 4. using a standard Tektronix J16 Option 02 Digital Photometer directed at an appropriately colored square presented steadily against a black background. This method of measurement has been shown to have results comparable to those obtained using flicker photometry (Pammer \& Lovegrove, 2000). The target was neutral gray and matched in luminance to the gray mask. All displays were presented on a uniform black surround (measured as $0.01 \mathrm{~cd} / \mathrm{m}^{2}$ ), which formed the background for the full monitor display.

The Michelson contrast of the display against the black background in a dark room $\left(<.01 \mathrm{~cd} / \mathrm{m}^{2}\right)$ was calculated to be .99 for all conditions.

The target and mask displays were viewed binocularly, and each was presented on the screen for a variable delay duration, as specified in the Procedure section below. The display sequence appeared randomly $1.2^{\circ}$ above or below the fixation point. The delay conditions had interstimulus intervals (ISIs) of $0,10,20,40,70,100$, and $160 \mathrm{msec}$. A target-alone condition was used as the baseline measure. Because the monitor refresh rate was approximately $17 \mathrm{msec}$, as measured by a photocell and oscilloscope, a close approximation to these times were actually used.

Procedure. The participants were familiarized with the displays through three practice sequences. The first 10 trials consisted of only the target display; the subsequent 10 trials consisted of both the target display and the mask display as presented in the actual experimental trials. This was then followed by 20 trials consisting of the target display and the mask display presented simultaneously (Hogben \& Di Lollo, 1984). The third practice set was designed to establish an individual display duration in order to achieve optimal responding. In order to establish this stimulus duration criterion, only the target was presented, and accuracy was required to be between $80 \%$ and $90 \%$ correct over 20 trials. If the participant failed to respond within these limits, the experimenter increased or decreased the duration of the target display accordingly until the participant was responding within the response criterion. The mask was presented for the same duration ultimately obtained for the target. The target display was increased or decreased in 17-msec steps to a minimum of $17 \mathrm{msec}$ and a maximum of 4 steps $(68 \mathrm{msec})$. As a result of this manipulation, display durations were idiosyncratic between participants. However, nonmonotonic metacontrast has been found over a range of target and mask durations-for example, $100 \mathrm{msec}$ (Merikle, 1977), $60 \mathrm{msec}$ (Bernstein, Proctor, Belcher, \& Schurman, 1974), and 50 msec (Proctor, Nunn, \& Pallos, 1983) whereas Arand and Dember (1978) varied target duration, keeping the mask duration constant at $105 \mathrm{msec}$. Therefore, it was not anticipated that the differences in target and mask durations would influence the nature of the metacontrast function.

The experiment was divided into two blocks, each block consisting of five sets of 54 trials in which delay conditions and color were randomized. The participants were given the opportunity to rest their eyes between the sets and the chance for a longer break between the blocks. At the beginning of the second block, the participant was required to respond again to the third set of practice trials in order to redetermine his/her stimulus duration criterion. Most participants improved over the first block, such that the duration of the displays was generally shorter in the second block of trials; however, there was no significant difference between the nature of the masking functions between the two blocks.

Each trial proceeded with a fixation point of one screen pixel appearing in the center of the screen for $500 \mathrm{msec}$. The fixation was followed $1 \mathrm{sec}$ later by the target, which was then followed by the mask at a randomly chosen ISI. The participants indicated which dot was missing from the target display via the right-hand numerical keypad, such that the locations of the nine numbers on the keypad corresponded to the nine dots in the target.

\section{Results and Conclusions}

Mean scores were generated for each condition for each participant, and these scores were then averaged over 
participants. The scores were then represented relative to baseline (e.g., Williams et al., 1991). Relative scores were calculated by determining the difference between the score for the delay condition and the score for the baseline in which target and mask were presented simultaneously. The mean scores are graphed in Figure 2. A two-way analysis of variance (ANOVA) performed on the data (color $\times$ delay) showed a significant main effect of delay $[F(7,126)=7.39, p<.001]$ but no effect of color $[F(2,36)=0.67$, n.s. $]$ and no color $\times$ delay interaction $[F(14,252)=1.27$, n.s.]. Error bars have been omitted because inclusion of them would have compromised the clarity of the graphs. The range of standard error $(S E)$ over all points was 2.7-3.6. Indeed, the $S E$ for all conditions was consistently around 3 , suggesting that the pattern of performance was consistent over all participants.

A polynomial analysis was conducted for each color condition over delay. The quadratic components were significant in all conditions (red mask, $F=7.103, p<$ .05 ; blue mask, $F=15.836, p<.05$; gray mask, $F=$ $13.822, p<.05)$.

The results suggest that the presence of the mask decreased responding in all conditions. No one color at any point increased responding above the baseline condition. The present experiment therefore failed to provide evidence for a differential effect of color on transient activity.

Previous studies (e.g., Williams et al., 1991; Williams et al., 1990) have been conducted under bright viewing conditions with very low contrast displays, whereas the present experiment was conducted in dark conditions with brighter displays. This difference was necessary be-

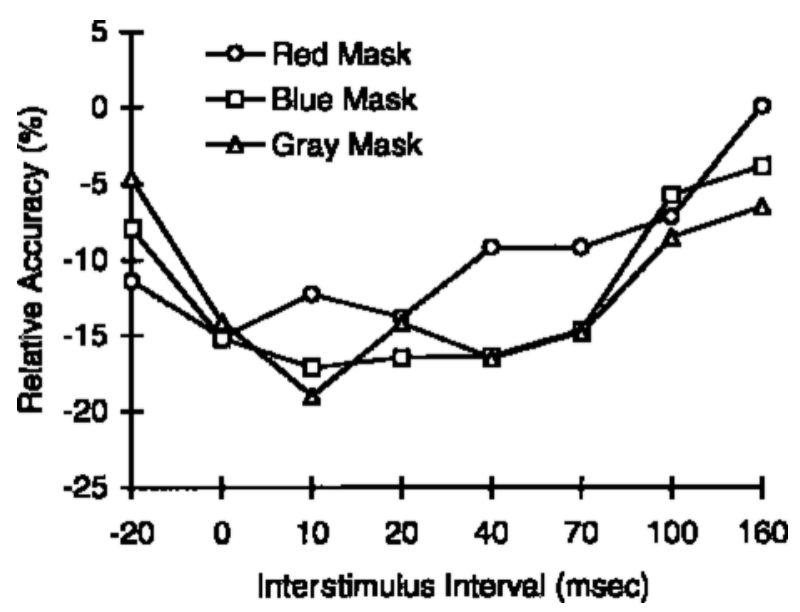

Figure 2. Percent correct relative to baseline as a function of interstimulus interval (ISI) for Experiment 1. ISI was used in this case, rather than the traditional SOA, because of variable display durations. SOA necessarily takes into account the length of time the target is presented; in this experiment, target duration was manipulated in order to establish criteria for responding. For this reason, ISI was considered to be the more appropriate measure. Because each delay condition spanned approximately $20 \mathrm{msec}$, and the participants responded between a range of approximately 10 and $80 \mathrm{msec}$, an ISI of -20 was arbitrarily chosen to reflect zero SOA. cause the present experiment used a small complex target. As such, a higher contrast between the target and the background was necessary to make the appropriate target discriminations. Indeed, informal pilot studies demonstrated that it was impossible to make target discriminations at very low luminance levels.

Nevertheless, if the effects of color on transient system activity are to be adopted as a basis for remedial techniques with reading-disabled children, the results must be reliable enough to be replicable over different populations, equipment, and environmental conditions. Experiment 2 was therefore designed to investigate this issue further by manipulating the conditions under which the experiment was conducted.

\section{EXPERIMENT 2}

Experiment 1 was conducted under dark ambient conditions; however, the nature of the rods and cones in the visual system and their different sensitivities to light and color suggest that an interaction between viewing conditions and psychophysical measurements may have been possible.

Photopic vision refers to light conditions above $10 \mathrm{~cd} / \mathrm{m}^{2}$ (Reeves, 1986), whereas scotopic vision refers to light levels much lower than this-for example, less than $0.01 \mathrm{~cd} / \mathrm{m}^{2}$ (Sekuler \& Blake, 1985 ) or $0.001 \mathrm{~cd} / \mathrm{m}^{2}$ (Travis, 1991) - and is more sensitive to light across the spectrum (except at very long wavelengths) than is photopic vision. The ambiguous area here is the mesopic range of retinal illumination, which spans from the lower range of photopic conditions to the upper levels of the scotopic region. In this level of illumination, both the rods and the cones mediate the visual response, and their relative contributions to color vision are difficult to assess. Certainly, the effect on color perception that accompanies the transition from photopic to scotopic conditions is well known and is referred to as the Purkinje shift. However, there is little clear knowledge regarding color perception within the mesopic range-that is, before the Purkinje shift-and what interactions may be occurring between rods and cones at this level (e.g., compare Frumkes, Sekuler, Barris, Reiss, \& Chalupa, 1973, Saugstad \& Saugstad, 1959, Stabell \& Stabell, 1976, and Vienot \& Chiron, 1992, for conflicting results). Furthermore, the sensitivity of the physiological system to color when it is in a state of flux, or adapting to one state, is even more uncertain.

Experiment 2 was therefore designed (1) to test the possibility that the lack of color effect demonstrated in Experiment 1 may reflect ambient lighting conditions and (2) to address the suggestion that color effects in metacontrast are dependent on environmental considerations.

\section{Method}

Participants. Thirty-eight students from first- and third-year undergraduate psychology courses at Wollongong University participated in this experiment. The first-year students received percentage points toward their end of session mark for participation. The third- 
year students participated as part of course requirement. Twentyone students participated in the dark condition, and 17 students participated in the light condition. Each participant was assessed according to the procedure in Experiment 1. The results for 2 participants in the light condition were removed due to ceiling effects.

Apparatus and Procedure. There were two different experimental conditions: the dark condition and the light condition. The two conditions differed in terms of their display luminances and general room luminance. The terms dark and light in this context refer to the different experimental conditions, whereas photopic and scotopic refer to the physical luminance. For the dark condition, the luminances of the masks were as follows: red, $14.5 \mathrm{~cd} / \mathrm{m}^{2}$; blue, $14.2 \mathrm{~cd} / \mathrm{m}^{2}$; and gray, $14.6 \mathrm{~cd} / \mathrm{m}^{2}$. A small tungsten globe in the corner of the room provided the room illumination.

For the light condition, the display luminances were as follows: red, $38 \mathrm{~cd} / \mathrm{m}^{2}$; blue, $37.5 \mathrm{~cd} / \mathrm{m}^{2}$; and gray, $38.5 \mathrm{~cd} / \mathrm{m}^{2}$. An overhead fluorescent light, which was covered with a single layer of black fabric to reduce the glare, illuminated the room. In all cases, measurements were based on the photopic luminosity function. The Michelson contrast between the displays and the screen background, measured under the respective viewing conditions, were .99 for the dark condition and .95 for the light condition.

All displays were generated by an IBM-compatible PC, with a Trident graphics card. The luminance values were measured according to the procedure used in Experiment 1. In general, the conditions were such that, in the dark condition, the participant saw a reasonably bright display in a dim room and, in the light condition, the participant saw a very bright display in a brightly lit room. In both conditions, the background screen specif ication was the same, at $\operatorname{RGB}(0,0,0)$. The ambient room luminances were measured to be $1 \mathrm{~cd} / \mathrm{m}^{2}$ for the light condition and $0.01 \mathrm{~cd} / \mathrm{m}^{2}$ for the dark condition. These values were taken from photometer recordings of a black computer screen under each of the light conditions.

The ISI conditions were as follows: simultaneous target and mask, 0, 10, 20, 40, 70, 100, and $150 \mathrm{msec}$. There was also a nomask condition. The target and mask display were the same as those in Experiment 1.

The experiment was conducted according to the procedure used in Experiment 1.

\section{Results and Conclusions}

In all analyses, the data were treated as specified in Experiment 1.

Again, there was a suggestion of a decrease in masking with the red mask in the light condition; however, as in Experiment 1 , this was not significant $[F(2,28)=0.56$, n.s.]. There was a significant effect of delay $[F(7,98)=21.77$, $p<.001]$ but no color $\times$ delay interaction $[F(14,196)=$ 1.49 , n.s.]. Figure 3 illustrates the mean difference scores relative to the baseline for each color condition.

A significant U-shaped metacontrast function was indicated by the polynomial analysis, which demonstrated significant quadratic functions for all color conditions over delay (red, $F=45.294, p<.001$; blue, $F=39.745$, $p<.001$; and gray, $F=35.454, p<.001$ ).

In the dark condition, however, there was a significant main effect of color, $[F(2,40)=3.51, p<.05]$, and a post hoc comparison confirmed a significant difference between the red and gray conditions $[F(1,20)=7.37$, $p<.25]$. A significant effect of delay was also demonstrated $[F(7,140)=16.61, p<.001]$, but there was no color $\times$ delay interaction $[F(14,280)=0.94$, n.s. $]$. As in Experiment 1, only a small and consistent range of $S E$

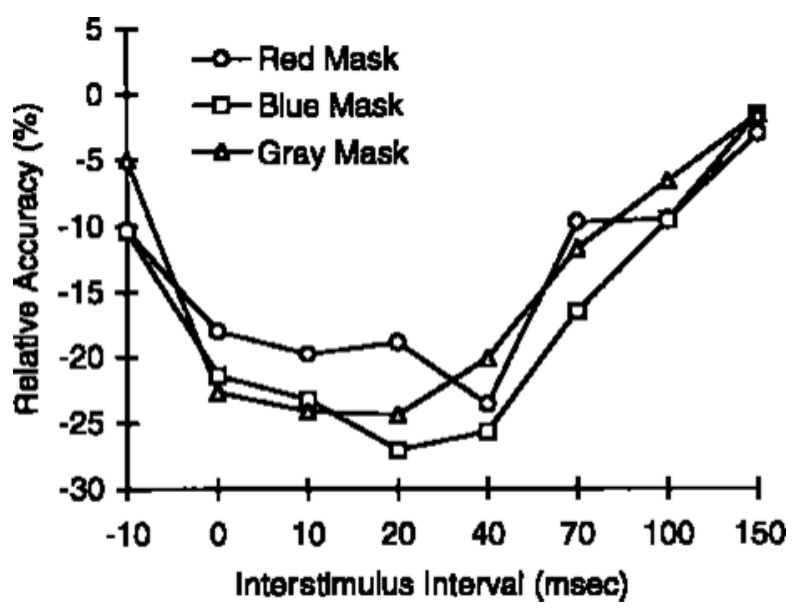

Figure 3. Percent correct relative to baseline as a function of interstimulus interval for each masking condition in Experiment 2 in the light condition.

(2.5-3.8) was produced in each condition, demonstrating a pattern similar to that in Experiment 1. Relative accuracy by delay for the dark condition is illustrated in Figure 4.

As with the light condition, the polynomial analyses revealed significant quadratic trends for all conditions (red, $F=25.745, p<.001$; blue, $F=36.334, p<.001$; and gray, $F=52.131, p<.001)$.

The analyses indicate that there was a significant effect of color in the dark condition, which was absent in the light condition. The results for the dark condition suggest that less masking overall is apparent with the red mask, compared to the blue and gray mask. This is consistent with the original hypothesis, which suggested that long wavelength light suppresses transient activity, thus resulting in less masking.

The results of the present experiment, together with those of other studies (e.g., Edwards et al., 1996), suggest that metacontrast differences on the basis of color may be obtained most clearly with bright displays on a dark background in darkened room illumination and reflect only a decrease in transient activity with red light.

Metacontrast, however, is a notoriously fickle function; the nature of the nonmonotonic pattern is dependent on such interrelated factors as relative luminance intensities of the displays (Cox \& Dember, 1971; Schiller, 1966), spatial contiguity (Cox \& Dember, 1971; Lefton, 1973), physical similarity (Uttal, 1970), retinal eccentricity (Breitmeyer, 1978; Turvey, 1973), contrast (Alpern, 1953; Fehrer \& Smith, 1962), and general luminance levels (Lefton \& Newman, 1976) —not to mention the fact that the transienton-sustained hypothesis is by no means the only candidate to explain the phenomenon (e.g., Burr, 1984; Di Lollo, Bischof, \& Dixon, 1993; Francis, 1997). It would seem reasonable, therefore, to adopt another psychophysical measure designed to simulate transient system activity. If it is the case that the results reported thus far in this 


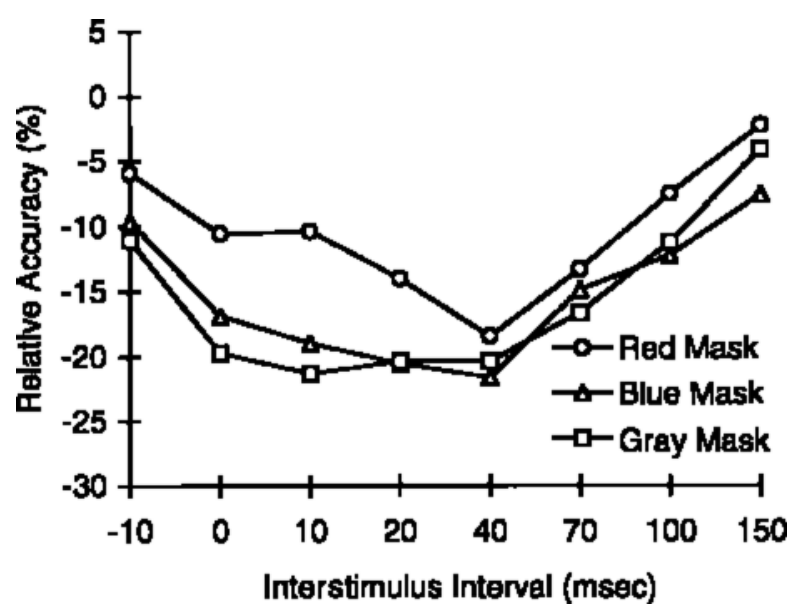

Figure 4. Percent correct relative to baseline as a function of interstimulus interval for each masking condition in Experiment 2 in the dark condition.

paper are dependent on methodological limitations, we would expect clear color differences in another measure designed to reflect transient system activity.

\section{EXPERIMENT 3}

Breitmeyer and Williams (1990) adopted an apparent motion design in which the displays were presented on isoluminant white, green, or red backgrounds. They found that the function relating the perception of motion to stimulus onset asynchrony (SOA) decreased with the red background, relative to the green or white backgrounds. They explained their results in terms of the suppression of the transient response by the red background resulting in a decrease in the perception of motion. Indeed, Slaghuis, Twell, and Kingstone (1996) presented normal and disabled readers with a Ternus apparent motion task. They found a decrease in the perception of group movement over element movement for reading-disabled individuals, relative to controls, which they similarly interpreted to reflect a decrease in transient system activity for the dyslexic readers. Using a similar Ternus apparent motion task on isoluminant colored backgrounds in the present experiment, it was predicted that the perception of group movement would increase for the blue background and decrease for the red background, reflecting increases and decreases, respectively, in transient system activity.

\section{Method}

Participants. Ten individuals from the general and academic psychology staff pool and the first-year introductory psychology course at the University of Wollongong participated in the experiment. The first-year students received 0.5 percentage points toward their final assessment grade for one 30-min session.

Apparatus. The stimuli consisted of three horizontally adjacent black squares (RGB $[0,0,0],<0.01 \mathrm{~cd} / \mathrm{m}^{2}$ ), each subtending $0.57^{\circ} \mathrm{VA}$. Each square was separated from the adjacent square by $1.7^{\circ} \mathrm{VA}$, and the entire display sequence appeared $1.4^{\circ} \mathrm{VA}$ above or below a fixation square presented in the center of the screen. The displays were presented on an isoluminant red, blue, green, yellow, or gray background. The background luminances for all color conditions were set at $20 \mathrm{~cd} / \mathrm{m}^{2}$, and the Michelson contrast was calculated at .99 . These luminance values were consistent with Slaghuis et al. (1996).

The displays were written in Turbo Pascal Version 7 and were presented on a 486 DX2-66 computer with a standard VGA graphics card using a Barco color monitor. The experiment was conducted in a darkened room, and luminance measures were conducted according to the procedure used in Experiment 1.

Procedure. A display sequence was constructed in the following way: The first frame consisted of the three squares (A, B, and C), presented either above or below the fixation point for $54 \mathrm{msec}$. This 
was followed by an ISI of $0,17,34,51,68,85$, or $102 \mathrm{msec}$. The second frame consisted of three display squares (B, C, and D), positioned such that Squares B and C spatially overlapped those in the first frame, and Square D replaced Square A (see Figure 5). The display oscillated between Frame 1 and Frame 2 until the participant was satisfied as to whether group or element movement was seen. With each experimental trial, the participant was instructed to continue to look at the display until he/she had determined whether group or element movement was seen. Group movement was defined as all three squares moving together from left to right; element movement was defined as the single outside square alternating between the left- and right-hand side of the display sequence, giving a "flicking" or "jumping" effect. On making a decision, the participant was required to press the appropriate response key. Each participant was told that there were no correct or incorrect answers but that a response was dependent on individual perception of the event.

At the beginning of each experimental session, the participant was presented with 20 practice trials, which consisted of only the longest and shortest ISI conditions. This was to facilitate the perceptions of either clear group or element movement. ISIs were randomized within blocks, and color was randomized between blocks; two blocks for each color were presented.

\section{Results and Conclusions}

The number of group movement responses (out of 20) was recorded for each participant. A graph of frequency of group motion by delay is presented in Figure 6. The mean of these scores over all subjects was entered into a $5 \times 7$ ANOVA ( 5 colors $\times 7$ delay conditions). The results indicated a significant effect of delay $[F(6,54)=65.66$, $p<.001]$ but no significant effect of color $[F(4,36)=0.73$, n.s.] and no color $\times$ delay interaction $[F(24,216)=$ 0.98 , n.s.].

It was predicted that the frequency of the perception of group movement would increase with the blue background and decrease with the red background. However, it is clear that the manipulation of color was unsuccessful: The perception of group movement was not influenced by background color. These results conflict with the theory that transient system activity is differentially

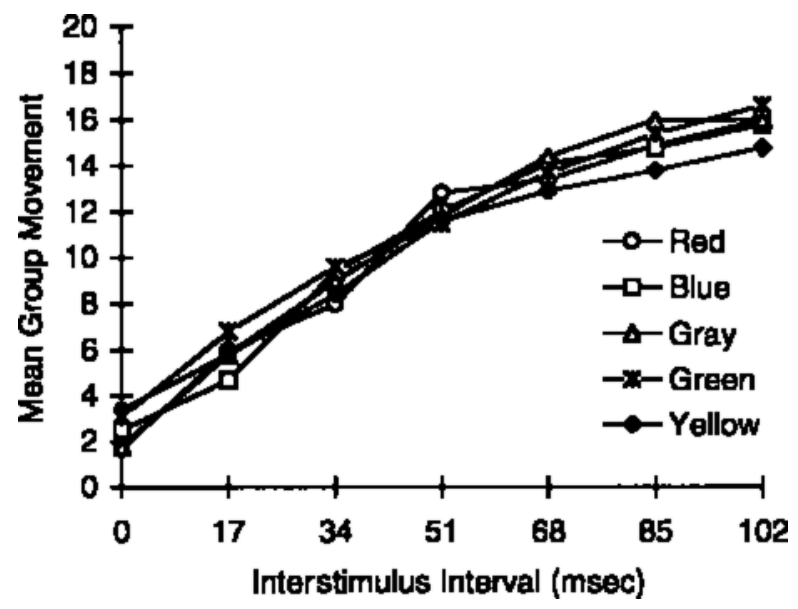

Figure 6. Reported frequency of the perception of group movement by delay, with different colored backgrounds in Experiment 3. influenced by color stimuli, but are consistent with the results obtained in the metacontrast Experiments 1 and 2.

\section{Interim Summary of Results}

The results from Experiments 1 and 2 using colored masks have demonstrated a trend for masking to decrease under red masking conditions; however, only in Experiment 2 was this clearly significant. The apparent motion task similarly failed to demonstrate any effect of color. Importantly, in all cases, the results clearly demonstrated the predicted psychophysical function appropriate to the paradigm: Clear U-shaped functions were demonstrated in all metacontrast conditions, and a positive function was demonstrated between ISI and perception of group motion in the apparent motion task. This would suggest that the intrinsic theoretical integrity of the methodologies have been maintained.

Therefore, the results thus far would appear to indicate that, on the basis of a population of adults with normal reading ability, there is no evidence for the suggestion that transient activity is enhanced under blue light conditions. Color, therefore, appears not to be a strong candidate for influencing transient activity to an extent that would advocate the use of colored stimuli as a remedial application for specific reading disability. However, it is not beyond the realm of possibility that the visual system in the child and/or reading-disabled child behaves somewhat differently from that of the adult, either in response to color or transient and sustained interactions that might result in differential masking effects. Therefore, Experiment 4 was designed to address this possibility by running the same metacontrast design with both normal and reading-disabled children.

\section{EXPERIMENT 4}

\section{Method}

Participants. Twenty primary school children in Canberra participated in the experiment. Of this group, 2 children could not get past the practice trials, and the data for 1 child was removed due to attentional difficulties. The final samples consisted of 10 control readers and 7 dyslexic readers, with an average age of 10.4 years and a range of $8-11.8$ years. This group of disabled readers was classified as reading impaired on the basis of a reading lag of 2 or more years, with cognitive development within the normal range and no contributing social, cognitive, or somatic disturbances, as determined through consultation with specialist teachers. General nonverbal cognitive performance was determined using the RAVENS Standard Progressive Matrices. The sample of control readers was of average cognitive development and reading ability as per teacher recommendation and conf irmed by the same tests. This sample was matched as closely as possible in terms of gender and age to the experimental group of readers.

Apparatus. The stimuli were the same as those used in Experiment 1 , presented on a 486 PC, running a standard VGA graphics card. All displays were $7.2 \mathrm{~cd} / \mathrm{m}^{2}$, presented on a black background. Although signif icant effects were found in the brighter conditions of Experiment 2, the present experiment was also a further attempt to replicate previous findings from studies using lower luminance levels.

Procedure. The procedure was fundamentally the same as that used in Experiment 1, with the following changes: Mask color was 


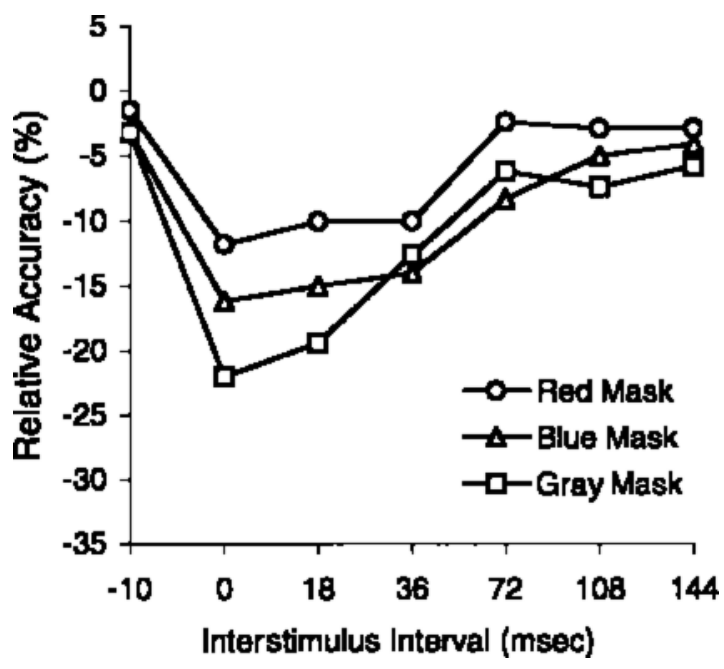

Figure 4. Percent correct relative to baseline as a function of interstimulus interval for each masking condition in Experiment 2 in the dark condition.

paper are dependent on methodological limitations, we would expect clear color differences in another measure designed to reflect transient system activity.

\section{EXPERIMENT 3}

Breitmeyer and Williams (1990) adopted an apparent motion design in which the displays were presented on isoluminant white, green, or red backgrounds. They found that the function relating the perception of motion to stimulus onset asynchrony (SOA) decreased with the red background, relative to the green or white backgrounds. They explained their results in terms of the suppression of the transient response by the red background resulting in a decrease in the perception of motion. Indeed, Slaghuis, Twell, and Kingstone (1996) presented normal and disabled readers with a Ternus apparent motion task. They found a decrease in the perception of group movement over element movement for reading-disabled individuals, relative to controls, which they similarly interpreted to reflect a decrease in transient system activity for the dyslexic readers. Using a similar Ternus apparent motion task on isoluminant colored backgrounds in the present experiment, it was predicted that the perception of group movement would increase for the blue background and decrease for the red background, reflecting increases and decreases, respectively, in transient system activity.

\section{Method}

Participants. Ten individuals from the general and academic psychology staff pool and the first-year introductory psychology course at the University of Wollongong participated in the experiment. The first-year students received 0.5 percentage points toward their final assessment grade for one 30-min session.

Apparatus. The stimuli consisted of three horizontally adjacent black squares (RGB $[0,0,0],<0.01 \mathrm{~cd} / \mathrm{m}^{2}$ ), each subtending $0.57^{\circ} \mathrm{VA}$. Each square was separated from the adjacent square by $1.7^{\circ} \mathrm{VA}$, and the entire display sequence appeared $1.4^{\circ} \mathrm{VA}$ above or below a fixation square presented in the center of the screen. The displays were presented on an isoluminant red, blue, green, yellow, or gray background. The background luminances for all color conditions were set at $20 \mathrm{~cd} / \mathrm{m}^{2}$, and the Michelson contrast was calculated at .99 . These luminance values were consistent with Slaghuis et al. (1996).

The displays were written in Turbo Pascal Version 7 and were presented on a 486 DX2-66 computer with a standard VGA graphics card using a Barco color monitor. The experiment was conducted in a darkened room, and luminance measures were conducted according to the procedure used in Experiment 1.

Procedure. A display sequence was constructed in the following way: The first frame consisted of the three squares (A, B, and C), presented either above or below the fixation point for $54 \mathrm{msec}$. This

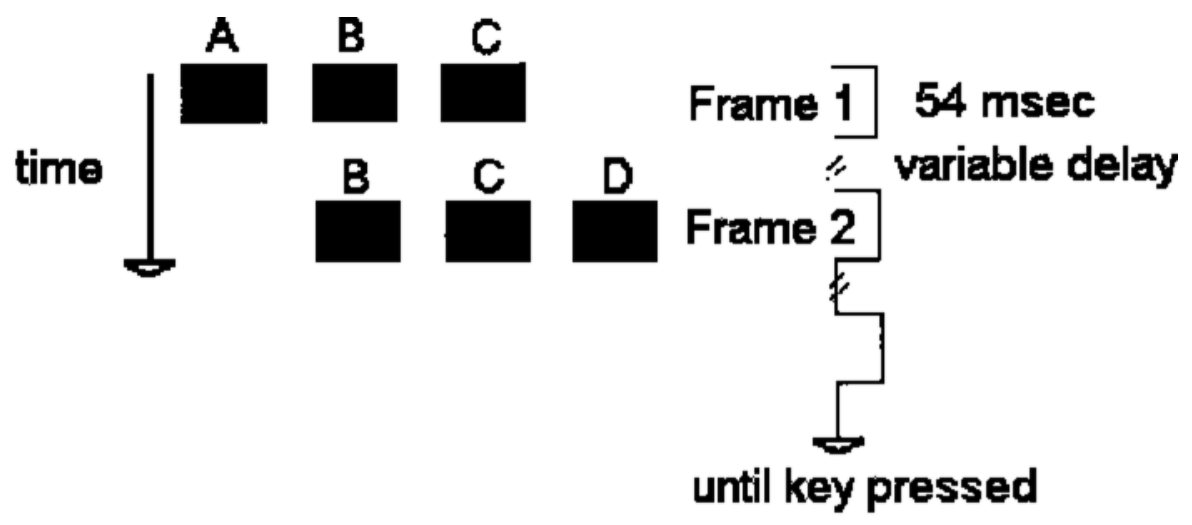

Element movement

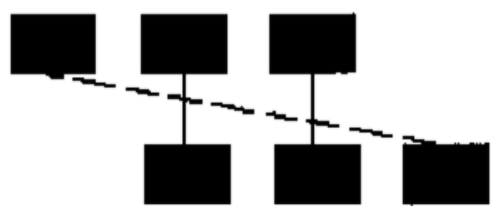

Group Movement

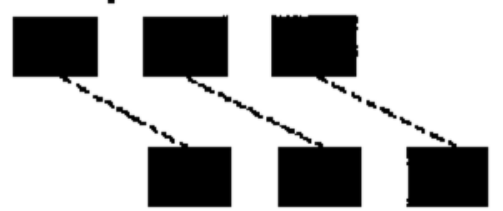

Figure 5. Displays and display sequence used in Experiment 3: apparent motion. 

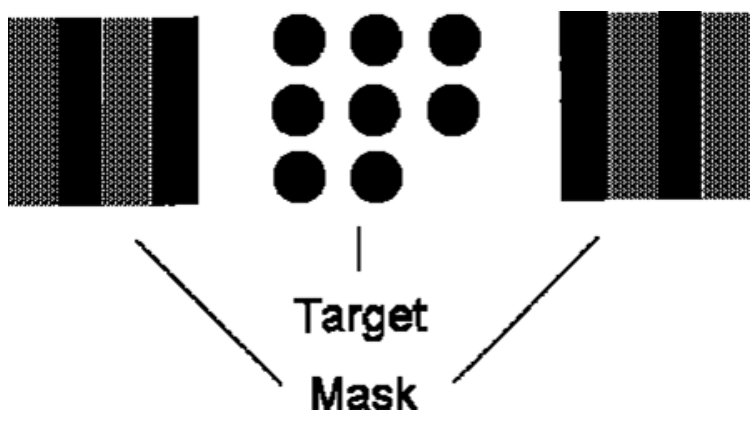

Figure 8. Target and mask displays used in Experiment 5.

$\times$ delay interaction $[F(12,108)=1.49$, n.s.]. Polynomial contrasts demonstrated significant quadratic components in all mask conditions (low contrast, $F=13.93, p<.05$; high contrast, $F=52.881, p<.001$; and medium contrast, $F=22.13, p<.001)$. Post hoc comparisons on the smallest difference revealed a significant difference between the medium- and low-contrast mask conditions $[F(1,9)=$ $10.64, p<.01]$ at Delay Condition $3(51 \mathrm{msec})[t(9)=$ $3.02, p<.01]$.

Progressively decreasing mask contrast resulted in a corresponding decrease in the metacontrast function. Therefore, the relative decrease in metacontrast has been demonstrated-however, not as predicted with an increase in wavelength but as a result of a decrease in mask contrast.

\section{GENERAL CONCLUSIONS}

One aim of this paper was to address some of the inconsistencies in the literature regarding the effect of color on transient activity - specifically, the proposal that red light attenuates transient activity, whereas blue light enhances it. This suggestion was explored in the context of a normal adult population and with normal and readingimpaired children. Three metacontrast experiments utilized color: In two experiments, the results implied the predicted effect of a decrease in masking with red light, whereas, in the other experiment, it was clearly significant. The general conclusion from this series of experiments is that, using metacontrast, it may be demonstrated psychophysically, that red light has a small but demonstrable effect in reducing the extent or degree of transient system activity under ideal psychophysical conditions, which is consistent with historical anatomical evidence. However, this result is not robust enough to extend to apparent motion. The same psychophysical conditions furthermore failed to show any effect of blue light on transient system activity. Finally, it was demonstrated that the change in the metacontrast function was simulated by decreasing the contrast of the masks. This result suggests that a confound between color and contrast may have been a factor in some of the psychophysical studies reviewed in the introduction. Therefore, although the findings from the studies reviewed in the introduction would appear consistent with an explanation in which the tran- sient system is differentially influenced by different color stimuli, a more parsimonious explanation is that broadband blue light influences transient activity by virtue of the luminance and/or contrast information inherent in the stimuli. There are a number of factors that may have contributed to this confound. One of these factors is the issue of contrast in color research. For example, consistent with Williams and colleagues (e.g., Williams et al., 1990: Williams et al., 1989), no attempt was made to equate color contrast over conditions. Therefore, it is certainly possible that the color contrast of the different isoluminant display colors may be a mitigating factor in the present design and is an issue that may become intrinsic to subsequent research. Furthermore, one cannot underestimate the difficulty in attempting to replicate computer-based experiments, given the variability in basic hardware specifications that alone can lend itself to tremendous fluctuations in stimuli criteria (e.g., Harris, Makepeace, \& Troscianko, 1987; Travis, 1991).

Unfortunately, in the present study, a more sophisticated representation of the color stimuli was impossible due to limitations in technical specifications regarding the computer monitors. Nevertheless, when it is necessary to explore such detail in order to explain data discrepancies, the basic premises of the study fail to be met. If the effect under question - the effect of blue on transient system activity - is critically sensitive to specific visual and environmental requirements, it would suggest that the effect, demonstrated by previous researchers, of blue light on transient system activity as measured psychophysically is not robust and is highly situation specific. Therefore, its use as the basis for remedial applications in such a diverse population as the specific reading disabled remains questionable, as does its theoretical significance.

Of course, it is possible that colored displays and/or stimuli are beneficial to the reading impaired individual for reasons unrelated to a transient deficit, or may be beneficial to a subgroup of dyslexic readers. For example, Wilkins et al. (1992), testing children who have been prescribed Irlen lenses, suggest that vascular disturbances may exist in some magnocellular cells for some children with reading difficulties that are more consistent with visual discomfort. Irrespective of optimal wavelength preference in the glasses themselves, another explanation also may lie in a unique utilization of chromatic and achromatic information from the photoreceptors by reading impaired individuals. In such a case, implications regard-

Table 1

Contrast and Space Average Luminance for the High-, Medium-, and Low-Contrast Masks in Experiment 5

\begin{tabular}{|c|c|c|c|c|}
\hline \multirow[b]{3}{*}{ Mask Type } & \multirow{2}{*}{\multicolumn{2}{|c|}{$\begin{array}{c}\text { Contrast Mask } \\
\text { Components }\end{array}$}} & \multirow[b]{3}{*}{$\begin{array}{c}\text { Contrast } \\
(\%)\end{array}$} & \multirow{3}{*}{$\begin{array}{c}\text { Space } \\
\text { Average } \\
\text { Luminance } \\
\left(\mathrm{cd} / \mathrm{m}^{2}\right) \\
\end{array}$} \\
\hline & & & & \\
\hline & $\begin{array}{c}\text { Light } \\
\left(\mathrm{cd} / \mathrm{m}^{2}\right)\end{array}$ & $\begin{array}{c}\text { Dark } \\
\left(\mathrm{cd} / \mathrm{m}^{2}\right)\end{array}$ & & \\
\hline High Contrast & 24.2 & .3 & 98 & 12.25 \\
\hline Medium Contrast & 19.6 & 4.9 & 60 & 12.25 \\
\hline Low Contrast & 14.2 & 10.9 & 13 & 12.55 \\
\hline
\end{tabular}




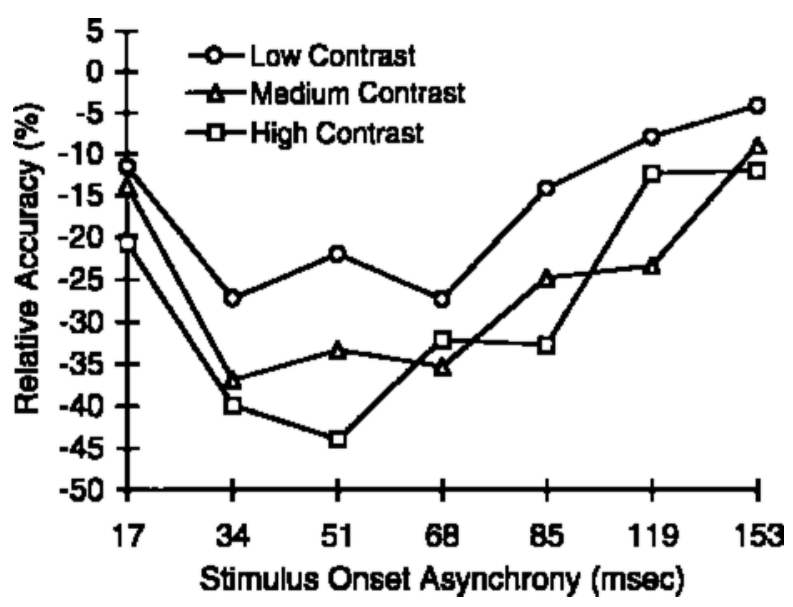

Figure 9. Relative accuracy over delay for high-, medium-, and low-contrast masks in Experiment 5.

ing the effects of color on transient cell activity transcend broadband color generated by the average computer monitor and may rely on visual processing anomalies of the individual. Such an explanation would presuppose no clear effect of color on transient neurones when using relatively unsophisticated color monitors and normal observers. As such, whenever discussing discrepancies in results over different laboratories, one cannot ignore the impact of different samples of participants (Hogben, 1996). Variations in sample criteria can result in substantial result variability. It is not implausible to suggest that studies that have demonstrated significant effects of color on a reading-impaired population may be exploiting subtle criteria differences in the sample. For example, Greer and Williams (1995) report using reading-disabled children from a specialist cognitive development clinic. Conversely, the children who participated in Experiment 4 of the present study were identified by teachers as reading impaired, relative to their peers within the school system. In other words, for either socioeconomic or personal reasons, their reading impairment was not overt enough to warrant specialist attention at an independent clinic. It is possible that children who are referred to specialist clinics may not only suffer from a reading disorder but may also have elements of other reading-related complaints, such as visual discomfort.

The results provided in this paper suggest that most transient/magnocellular cells in normal adult observers and in reading-disabled and normal reading children are insensitive to all colors except diffuse red light. This questions the wisdom of pursuing research into the remedial implications of broadband color for reading-disabled children independently of criteria considerations when the basis of such reports remains a mystery.

\section{REFERENCES}

Alpern, M. (1953). Metacontrast. Journal of the Optical Society of America, 43, 648-657.

Arand, D., \& Dember, W. M. (1978). The effect of luminance on meta- contrast with internally contoured targets. Bulletin of the Psychonomic Society, 11, 57-59.

Bernstein, I. H., Proctor, R. W., Belcher, J., \& Schurman, D. L. (1974). An analysis of U-shaped metacontrast. Perception \& Psychophysics, 16, 329-336.

Brannan, J., \& Williams, M. (1988). The effects of age and reading ability on flicker thresholds. Clinical Vision Sciences, 3, 137-142.

Breitmeyer, B. G. (1978). Disinhibition in metacontrast masking of vernier acuity targets: Sustained channels inhibit transient channels. Vision Research, 18, 1401-1405.

Breitmeyer, B. G. (1984). Visual masking: An integrative approach. New York: Oxford University Press.

Breitmeyer, B. G., \& Breier, J. (1993). Effects of background color on reaction time to stimuli varying in size and contrast: Inferences about human M channels. Vision Research, 34, 1039-1045.

Breitmeyer, B. G., May, J. G., \& Heller, S. S. (1991). Metacontrast reveals asymmetries at red-green isoluminance. Journal of the Optical Society of America, 8, 1324-1329.

Breitmeyer, B. G., \& Williams, M. (1990). Effects of isoluminantbackground color on metacontrast and stroboscopic motion: Interactions between sustained (P) and transient (M) channels. Vision Research, 30, 1069-1075.

BURR, D. (1984). Summation of target and mask metacontrast stimuli. Perception, 13, 183-192.

Cornelissen, P., Richardson, A., Mason, A., Fowler, S., \& Stein, F. (1995). Contrast sensitivity and coherent motion detection measured at photopic luminance levels in dyslexics and controls. Vision Research, 35, 1483-1494.

Cox, S. I., \& Dember, W. N. (1971). Effects of target-field luminance, interstimulus interval, and target-mask separation on extent of visual backward masking. Psychonomic Science, 22, 79-80.

Di Lollo, V., Bischof, W. F., \& Dixon, P. (1993). Stimulus-onset asynchrony is not necessary for motion perception or metacontrast masking. Psychological Science, 4, 260-263.

Edwards, V. T., Hogben, J. H., Clark, C. D., \& Pratt, C. (1996). Effects of a red background on magnocellular functioning in average and specifically disabled readers. Vision Research, 36, 1037-1045.

Fehrer, E., \& Smith. E. (1962). Effect of luminance ratio on masking. Perceptual \& Motor Skills, 14, 143-153.

FrANCIS, G. (1997). Cortical dynamics of lateral inhibition: Metacontrast masking. Psychological Review, 104, 572-594.

Frumkes, T., Sekuler, M., Barris, M., Reiss, E., \& Chalupa, L. (1973). Rod-cone interaction in human scotopic vision: I. Temporal analysis. Vision Research, 13, 1269-1282.

GreEr, A., \& Williams, M. (1995, April). Visual timing and wavelength effects in dyslexic and normal children. Paper presented at the meeting of the Society for Research in Child Development, Indianapolis.

Gross-Glenn, K., Skottun, B. C., Kushch, A., Lingua, R., Dunbar, M., Jallad, B., Lubs, H. A., Levin, B., Rabin, M., Parke, L., \& DuARA, R. (1995). Contrast sensitivity in dyslexia. Visual Neuroscience, 12, 153-163.

Harris, J. P., Makepeace, A. P., \& Troscianko. T. S. (1987). Cathode ray tubes displays in psychophysical research. Journal of Psychophysiology, 4, 413-429.

Hicks, T. P., LeE, B. B., \& Vidyasager, T. R. (1983). The responses of cells in macaque lateral geniculate nucleus to sinusoidal gratings. Journal of Physiology, 337, 183-200.

Hogben, J. H. (1996). A plea for purity. Australian Journal of Psychology, 48, 127-177.

Hogben, J. H., \& Di Lollo, V. (1984). Practice reduces suppression in metacontrast and in apparent motion. Perception \& Psychophysics, 35, 441-445.

IrLEN, H. (1983). Scotopic sensitivity and reading disability. Paper presented at the 91 st Annual Convention of the American Psychological Association, Anaheim.

Kremers, J., Lee, B. B., \& Kaiser, P. K. (1992). Sensitivity of macaque retinal ganglion cells and human observers to combined luminance and chromatic temporal modulation. Journal of the Optical Society of America, 9, 1477-1485.

KRUGER, J. (1979). Responses to wavelength contrast in the afferent visual systems of the cat and the rhesus monkey. Vision Research, 19, 1351-1358. 
Lee, B. B., Martin, P. R., \& VAlberg, A. (1989). Nonlinearity of summation of M- and L-cone inputs to phasic retinal ganglion cells of the macaque. Journal of Neuroscience, 9, 1433-1442.

Lee, B. B., Pokorny, J., Smith, V. C., Martin, P. R, \& Valberg, A. (1990). Luminance and chromatic modulation sensitivity of macaque ganglion cells and human observers. Journal of the Optical Society of America, 7, 2223-2236.

Lefton, L. A. (1973). Spatial factors in metacontrast. Perception \& Psychophysics, 14, 497-500.

Lefton, L. A., \& Newman, Y. (1976). Metacontrast and paracontrast: Both photopic and scotopic luminance levels yield monotones. Bulletin of the Psychonomic Society, 8, 435-438.

LegGe, G. E., \& Rubin. G. S. (1986). Psychophysics of reading. IV. Wavelength effects in normal and low vision. Journal of the Optical Society of America, 3, 40-51.

Lehmkuhle, S., Garzia, R., Turner, L., Hash, T., \& Baro, J. (1993). A defective visual pathway in children with reading disability. New England Journal of Medicine, 328, 989-996.

LENNIE, P. (1980). Parallel visual pathways: A review. Vision Research, 20, 561-594.

Livingstone, M. S., \& Hubel, D. H. (1987). Psychophysical evidence for separate channels for the perception of form, color, movement and depth. Journal of Neuroscience, 7, 3416-3468.

Livingstone, M. S., Rosen, G. D., Drislane, F. W., \& Galaburda, A. M. (1991). Physiological and anatomical evidence for a magnocellular defect in developmental dyslexia. Proceedings of the $\mathrm{Na}$ tional Academy of Sciences, 88, 7943-7947.

Lovegrove, W., Bowling, A., Badcock, D., \& Blackwood, M. (1980). Specific reading disability: Differences in contrast sensitivity as a function of spatial frequency. Science, 210, 439-440.

Lovegrove, W., \& Williams, M. (1993). Visual temporal processing deficits in specific reading disability. In D. Willows., R. Kruk, \& E. Corcos (Eds.), Visual processes in reading and reading disabilities (pp. 311-329). Hillsdale, NJ: Erlbaum.

Martin, F., \& Lovegrove, W. (1987). Flicker contrast sensitivity in normal and specifically disabled readers. Perception, 16, 215-221.

May, J., DunlaP, W., \& Lovegrove, W. (1992). Factor scores derived from visual evoked potential latencies differentiate good and poor readers. Clinical Vision Sciences, 7, 67-70.

May, J., Lovegrove, W., Martin, F., \& Nelson, W. (1991). Patternelicited visual evoked potentials in good and poor readers. Clinical Vision Sciences, 7, 67-70.

Merikle, P. (1977). On the nature of metacaontrast-With complex targets and masks. Journal of Experimental Psychology: Human Perception \& Performance, 3, 607-621.

Pammer, K., \& Lovegrove, W. A. (2000). A psychophysical study of the influence of color displays on the transient visual pathway. Manuscript submitted for publication.

Proctor, R. W., Nunn, M. B., \& Pallos, I. (1983). The influence of metacontrast masking on detection and spatial-choice judgments: An apparent distinction between automatic and attentive response mechanisms. Journal of Experimental Psychology: Human Perception \& Performance, 9, 278-287.

Reeves, A. (1986). Pathways in Type-B (U-shaped) metacontrast. Perception, 15, 163-172.

Saugstad, P., \& SAugstad, A. (1959). The duplicity theory: An evaluation. Advances in Ophthalmology, 9, 1-51.

SCHILLER, P. H. (1966). Forward and backward masking as a function of relative overlap and intensity of test and masking stimuli. Perception \& Psychophysics, 1, 161-164.

Sekuler, R., \& Blake, R. (1985). Perception. New York: Knopf.

Slaghuis, W., \& Lovegrove, W. (1985). Spatial frequency mediated visible persistence and specific reading disability. Brain \& Cognition, 4, 219-240.

Slaghuis, W., Twell, A. J., \& Kingstone, K. R. (1996). Visual and language processing disorders are concurent in dyslexia and continue into adulthood. Cortex, 32, 413-438.

Solman, R., CHO, H. S., \& DAIN, S. (1991). Colour-mediated grouping effects in good and disabled readers. Ophthalmic \& Physiological Optics, 11, 320-327.

Stabell, B., \& Stabell, U. (1976). Rod and cone contributions to peripheral colour vision. Vision Research, 16, 1099-1104.

Travis, D. (1991). Effective colour displays; Theory and practice. Cambridge: Cambridge University Press.

TurveY, M. T. (1973). On peripheral and central processes in vision: Inferences from an information-processing analysis of masking with patterned stimuli. Psychological Review, 80, 1-52.

UtTaL, W. R. (1970). On the physiological basis of masking with dotted visual noise. Perception \& Psychophysics, 7, 321-327.

Vidyasagar, T. R., \& Pammer, K. (1999). Impaired visual search in dyslexia relates to the role of the magnocellular pathway in attention. NeuroReport, 10, 1-5.

Vienot, F., \& Chiron, A. (1992). Brightness matching and flicker photometric data obtained over the full mesopic range. Vision Research, 32, 533-540.

WALther-Müller. P. U. (1995). Is there a deficit of early vision in dyslexia? Perception, 24, 919-936.

Wiesel, T. N., \& Hubel, D. H. (1966). Spatial and chromatic interactions in the lateral geniculate body of the rhesus monkey. Journal of Neurophysiology, 29, 1115-1156.

Wilkins, A. J., Milroy, R., Nimmo-Smith, I., Wright, A., Tyrrell, R., Holland, K., Martin, J., Bald, J., Yale, S., Miles, T., \& NoAKES, T. (1992). Preliminary observations concerning treatment of visual discomfort and associated perceptual distortion. Ophthalmic \& Physiological Optics, 12, 257-263.

Williams, M., Breitmeyer, B., Lovegrove, W., \& Gutierrez, C. (1991). Metacontrast with masks varying in spatial frequency and wavelength. Vision Research, 31, 2017-2023.

Williams, M., \& LeCluyse, K. (1990). Perceptual consequences of a temporal processing deficit in reading disabled children. Journal of the American Optometric Association, 61, 111-121.

Williams, M., LeCluyse, K., \& Bologna, N. (1990). Masking by light as a measure of visual integration time and persistence in normal and disabled readers. Clinical Vision Sciences, 5, 335-343.

Williams, M., LeCluyse, K., \& Rock-Faucheux, A. (1992). Effective interventions for reading disability. Journal of the American $\mathrm{Op}$ tometric Association, 63, 411-417.

Williams, M., \& Lovegrove, W. (1992). Sensory and perceptual processes in reading disability. In J. Brannan (Ed.), Applications of parallel processing in vision (pp. 263-302). New York: Elsevier.

Williams, M., Molinet, K., \& LeCluyse, K. (1989). Visual masking as a measure of temporal processing in normal and disabled readers. Clinical Vision Sciences, 4, 137-144.

(Manuscript received February 11, 1999; revision accepted for publication May 15, 2000.) 